\title{
ОПРЕДЕЛЕНИЕ РАЗЛИЧНЫХ ФЕНОЛОВ РЕАКЦИЕЙ С 4-АМИНОАНТИПИРИНОМ
}

В основу широко распространенного колориметрического метода определения фенолов в растворах положена реакция их с 4-аминоантипирином (ААП), причем чувствительность метода достигает $10^{-7} 2$ [1]. Реакция представляет собой электрофильное замещение водорода в пара-положении аминопиразолоном с образованием сильно окрашенного продукта реакции - антипирилхинонимина и эффективна в щелочной среде ( $\mathrm{pH}$ $9-10)$ и в присутствии окислителя, чаще всего - феррицианида калия $\left[{ }^{2}\right]$. Эта реакция изучена главным образом эмпирически - для выяснения условий достижения устойчивости красителя $\left[{ }^{3,4}\right]$, селективного определения пирокатехина $\left[{ }^{5}\right]$ и в последние годы для определения фенолов в сточных водах $\left[{ }^{6-8}\right]$. Мало исследованы до сих пор особенности протекания реакции ААП с различными замещенными фенолами, т. е. влияние на ее ход структуры фенола [ $\left.{ }^{6-11}\right]$.

Нами сделана попытка выяснить возможности применения ААП-метода для определения фенолов, часто встречающихся в окислительных смесях ввиду своей высокой способности к окислению.

\section{Материал и методика}

Исследовалось 30 одноатомных и 15 многоатомных замещенных фенолов (табл. 1 и 3). Все алкилрезорцины (характеристику см. $\left[{ }^{12,13}\right]$ ), кроме 5-метилрезорцина, синтезированы и любезно предоставлены нам Ю. Лилле [ $\left.{ }^{14}\right]$.

Реакция проводилась путем добавки к 5,0 мл водного раствора фенола заданной концентрации (табл. 1) 0,03 мл $2 \%$-ного раствора ААП («ч», Chemapol), затем $0,1 \mu \Omega 2$ н. раствора $\mathrm{NH}_{4} \mathrm{OH}$ и 0,1 мл $2 \%$-ного раствора $\mathrm{K}_{3} \mathrm{Fe}(\mathrm{CN})_{6}$. После взбалтывания раствора на нефелометре ФЭК-56 М с синим светофильтром № $5(490 \pm 10$ нм) при толщине слоя 10,055 м.м измерялась его оптическая плотность. Контролем служила смесь тех же реактивов без фенола. Для фенолов, не образующих с ААП окрашенного продукта, сняты спектры поглощения в УФ-области на приборе «Specord UV VIS».

\section{Результаты и их обсуждение}

Реакция с образованием окрашенного хинонимина наблюдалась у 29 фенолов из 45 (см. табл. 1), причем минимальное количество фенолов для их определения составляло $1-10 \cdot 10^{-8}$ моля $\left(1-10 \cdot 10^{-6}\right.$ г). 
Результаты определения фенолов реакцией с ААП

\begin{tabular}{|c|c|c|c|c|}
\hline \multirow{2}{*}{ Фенол } & \multicolumn{2}{|c|}{$\begin{array}{l}\text { Коэффициент погло- } \\
\text { щения красителя } \varepsilon\end{array}$} & \multirow{2}{*}{$\begin{array}{c}\text { Область } \\
\text { измерения } \\
\cdot 10^{-6}, M\end{array}$} & \multirow{2}{*}{ Окраска } \\
\hline & $\Omega / \mu O \Omega b \cdot C M$ & $\begin{array}{c}\% \text { от } \\
\text { фенола }\end{array}$ & & \\
\hline Фенол & 12000 & 100 & $2-40$ & Пурпурная \\
\hline 2-Метилфенол & 9700 & 81 & $2-60$ & Вншневая \\
\hline 2-Аллилфенол & 9200 & 77 & $8-100$ & Малиновая \\
\hline 2,3 -Диметилфенол & 8500 & 71 & $8-104$ & Вишневая \\
\hline 2,5 -Диметилфенол & 8100 & 68 & $8-640$ & Вишневая \\
\hline Пирокатехин & 6800 & 57 & $5-200$ & Красная \\
\hline 3-Этил-5-метилфенол & 6500 & 54 & $4-180$ & Фиолетовая \\
\hline Флуороглюцин & 6500 & 54 & $4-104$ & Красновато-бурая \\
\hline Резорцин & 5500 & 46 & $2-100$ & Красная \\
\hline 2-Пропилфенол & 5200 & 43 & $1-1000$ & Малиновая \\
\hline 5-Гептилрезорцин & 4900 & 41 & $4-160$ & Пурпурная \\
\hline 2-Вторбутилфенол & 4800 & 40 & $8-200$ & Желтовато-красная \\
\hline 3,5 -Диметилфенол & 4500 & 38 & $8-170$ & Фиолетовая \\
\hline 5-Децилрезорцин & 4300 & 36 & $4-260$ & Пурпурная \\
\hline $2,3,5$-Триметилфенол & 3300 & 28 & $8-160$ & Красная \\
\hline 2-Гексилрезорцин & 3200 & 27 & $8-400$ & Желтовато-красная \\
\hline 2-Бутилрезорцин & 3000 & 25 & $10-400$ & Желтовато-красная \\
\hline 2-Метилрезорцин & 2800 & 23 & $22-210$ & Желтовато-красная \\
\hline 2-Пропилрезорцин & 2500 & 21 & $6-360$ & Желтовато-красная \\
\hline 4-Метилфенол & 2300 & 19 & $10-520$ & Красная \\
\hline 2-Нонилрезорцин & 2200 & 18 & $15-180$ & Желтовато-красная \\
\hline 2-Гексил-5-Метилрезорцин & 1900 & 16 & $16-300$ & Оранжевая \\
\hline 2-Нонил-5-метилрезорцин & 1700 & 14 & $2-100$ & Оранжевая \\
\hline 3-Метилфенол & 1500 & 12 & $10-500$ & Красная \\
\hline 3-Третбутилфенол & 1300 & 11 & $20-1100$ & Желтовато-красная \\
\hline 5-Метилрезорцин & 900 & 8 & $6-350$ & Желтовато-красная \\
\hline 2, 6-Диметилфенол & 800 & 7 & $40-1000$ & Красная \\
\hline $2,4,6$-Триметилфенол & 800 & 7 & $40-1000$ & Красная \\
\hline То же * & 270 & 2 & $80-1100$ & Желтовато-красная \\
\hline Пирогаллол & 260 & 2 & $100-1000$ & Сероватая \\
\hline
\end{tabular}

При меч ание: * Доза реактивов в 4 раза больше, т. е. 0,3 мл ААП, 0,4 мл $\mathrm{NH}_{4} \mathrm{OH}$ и 0,4 мл $\mathrm{K}_{3} \mathrm{Fe}(\mathrm{CN})_{6}$.

Вместо общепринятого объема фенольного раствора -50 мл - мы использовали объем 5 мл, который больше соответствовал нашей методике. Сравнение показало, что результаты исследований оксибензола в обоих случаях тождественны, при исследовании пирокатехина чувствительность реакции повысилась почти в 10 раз (концентрационный интервал для 50 мл раствора $10-800 \cdot 10^{-6} M$, а для пробы 5,0 м $5-200$. $\left.\cdot 10^{-6} M\right)$, причем интенсивность окраски за один и тот же промежуток времени возрасла на $30 \%$. Учитывая, что при определении пирокатехина окислителем вместо феррицианида калия служит кислород воздуха, вероятной причиной этого эффекта можно считать относительное увеличение количества кислорода в разбавленном растворе и облегчение его диффузии в более тонком слое жидкости. Для 5-метилрезорцина концентрационный интервал при пробе 5 мл составляет $6-350 \cdot 10^{-6} M$ против $36-200 \cdot 10^{-6} M$ для 50 мл раствора. Окраска раствора в первом случае более интенсивная (на $20-30 \%$ ).

Заместители должны оказывать влияние на активность гидроксильной группы (облегчать или затруднять отделение протона) и реакционную способность бензольного ядра, в котором реакционным центром яв- 
ляется углеродный атом в пара-положении. Для всех изученных нами заместителей установлено ускоряющее влияние их на электрофильное замещение, причем скорость реакции тем выше, чем больше аддитивная сумма резонансных постоянных заместителей. При этом у 2-, 3- и 4-метилзамещенных устойчивая окраска образуется только через 20 мин после смешивания реактивов, у остальных фенолов сразу же. Кроме того, под влиянием таких заместителей увеличивается и реакционная способность к автоокислению хинонимина, т. е. снижается стабильность красителя, особенно в случае многоатомных фенолов (табл. 3).

Влияние заместителей на поглощенную окраску проявляется следующим образом: орто-заместители, обладая гиперхромным эффектом, смещают поглощенный цвет в направлении фиолетовой области. Два заместителя в мета-положении вызывают углубление цвета, т. е. обладают батохромным эффектом. В результате появляются дополнительные цвета, у одних - желтоватый, у других - фиолетовый, в то время как у оксибензола - пурпурный.

Данные табл. 1 по интенсивности окраски хинонимина свидетельствуют о том, что всегда при замещении бензольного ядра алкильными, метокси- и гидроксильными группами снижается коэффициент поглощения. Значительнее других (от 19 до 100\%) интенсивность окраски хинонимина снижают заместители в орто-положении в ряду $\mathrm{CH}_{2} \mathrm{C}_{6} \mathrm{H}_{5}>$ $>\mathrm{CH}\left(\mathrm{CH}_{3}\right)\left(\mathrm{C}_{2} \mathrm{H}_{5}\right)>\mathrm{C}_{3} \mathrm{H}_{7}>\mathrm{OH}>\mathrm{CH}_{2}=\mathrm{CH}-\mathrm{CH}_{2}>\mathrm{CH}_{3}$. Однако суммарное влияние заместителей не является аддитивным. Так, для $\left(\mathrm{CH}_{3}\right)_{2}$ снижение составляет 93\%. Орто-заместители могут стерически препятствовать как отделению протона, так и сопряжению гидроксильной группы с красителем (сопряженная хромофорная цепь) вследствие нарушения копланарности ядра. Судя по данным литературы $\left[{ }^{15}\right]$, последний момент, очевидно, менее важен, поскольку у соединений сходной структуры одна метильная группа в орто-положении к гидроксилу вызывает поворот системы на $24^{\circ}$ по сравнению с копланарным расположением. У 2,3- $\left(\mathrm{CH}_{3}\right)_{2}$ этот угол равен $39^{\circ}$, у $2,6-\left(\mathrm{CH}_{3}\right)_{2}-55^{\circ}$ и у $2,3,5,6,-\left(\mathrm{CH}_{3}\right)_{4}-$ $72^{\circ}$. Таким образом, 2,3,5-триметилфенол менее копланарен по сравнению с 2,6-диметилфенолом, интенсивность окраски снижает только на $72-86 \%$.

По данным $[2,6,8]$, пара-алкилфенолы, в том числе и метилпроизводные, не реагируют с ААП, поскольку эти группы не отщепляются. Тем не менее нами получен для ААП устойчивый хинонимин с 4-метилфенолом, интенсивность окраски у которого на $81 \%$ меньше, чем у фенола. Интересно отметить, что $\mathrm{CH}_{3}$-группа при обычных условиях отшепляется даже у 2,4,6-триметилфенола. Увеличение жесткости условий (большой избыток окислителя и ААП, см. табл. 1) значительно повышает интенсивность окраски. У остальных триметилфенолов, а также у 2-метокси-4-метилфенола метильная группа не отщепляется, равно как и другие алкильные группы (табл. 2).

Устойчивостью отличаются хинонимины, полученные только на основе одноатомных фенолов. Интенсивность окраски раствора даже после 24 а стояния на свету при комнатной температуре мало изменяется. Но продукт реакции двухатомных фенолов быстро светлеет (табл. 3). Повышенной стабильностью к дальнейшему окислению и интенсивностью окраски (на $17 \%$ ) получаемого красителя объясняется предпочтение, которое отдается сочетанию пирокатехина с ААП в присутствии кислорода воздуха в сравнении с $\mathrm{K}_{3} \mathrm{Fe}(\mathrm{CN})_{6}$.

Перечень фенолов, не реагирующих с ААП, и характеристики их УФ-спектров в нейтральном водном растворе даны в табл. 2, откуда видно, что коэффициенты поглощения фенолов мало зависят от строения 
Таблица 2

Коэффициенты поглощения (ع) в УФ-области для фенолов, не образующих окраску с ААП

\begin{tabular}{l|l|l}
\hline Фенол & $\lambda_{\max }, \mu \mu$ & $\varepsilon, \lambda / \mu о л b \cdot c M$ \\
\hline
\end{tabular}

Данные собственного эксперимента

3-Третбутилфенол *

4, 6-Дитретбутилрезорцин

294

284

2-Метокси-4-метилфенол

282

$2,3,4$-Триметилфенол

283

2 -Бензилфенол

2, 4-Дитретбутилфенол

4-Вторбутилфенол

4-Третоктилфенол

267

277

279

4-Третбутилфенол

4-Пропилфенол

284

280

280

4-Изопропилфенол

4-Бензилфенол

280

282

$3,4,5$-Триметилфенол

278

2,6 -Дитретбутил-4-метилфенол

272

278

$2,4,6$-Триметилфенол

$2,4,6$-Тритретбутилфенол

276

2,6-Диметоксифенол

Пирогаллол *

269

262

3200

3030

2965

2750

2420

2125

2075

1980

1875

1840

1775

1770

1720

1670

1670

1545

1142

662

Данные $\left[{ }^{1}\right]$, в щелочном растворе

Фенол *

2-Метилфенол *

3-Метилфенол *

$287 \quad 2400$

$289 \quad 2900$

$289 \quad 2400$

4-Метилфенол *

2600

2, 4-Диметилфенол

2,5 -Диметилфенол *

295

296

292

295

3,4 -Диметилфенол

3,5 -Диметилфенол *

290

2900

3500

2800

2500

Пр и меч ан и е: * Образует окраску с ААП (см. табл. 1).

Таблица ร

Стабильность замещенных хинониминов

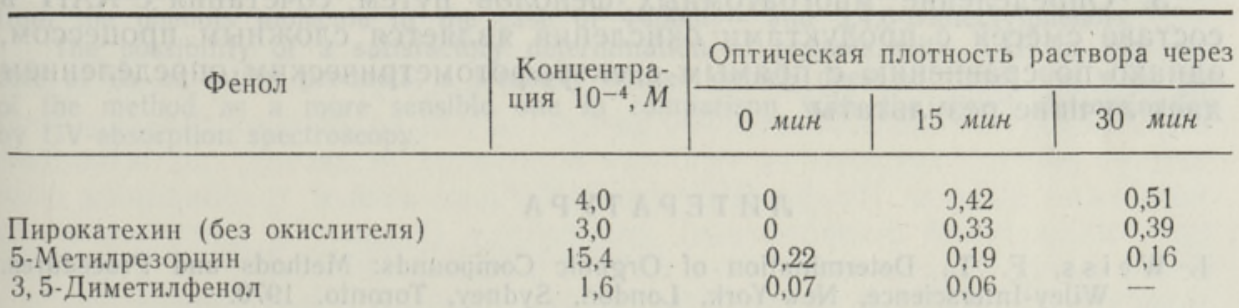

заместителей, а в бо́льшей мере - от их количества и положения. Почти во всех случаях заместители повышают оптическое поглощение фенола.

Определение фенолов в составе реакционных смесей в процессах их окисления значительно затруднено из-за влияния продуктов окисления, обладающих близкой к исходному фенолу структурой. Нами изучены реакционные смеси процессов автоокисления молекулярным кислородом $\left[{ }^{16}\right]$ и воздействием инициированных УФ- и $\gamma$-излучениями $\left({ }^{60} \mathrm{Co}\right)$ $\left[{ }^{12,13}\right]$ электрических импульсных (ӘИ) разрядов [17], а также при биохимнческом (бактериальном) окислении на активных илах [18]. Окрашен- 
ные продукты в основном образуются при автоокислении в щелочной среде и при ЭИ-обработке.

Простые одноатомные фенолы при окислении окрашиваются слабо, а красители на их базе обладают высокими коэффициентами поглощения. Поэтому они легко определимы с помощью ААП и в окислительных смесях. Трудности возникают в случае окисления многоатомных фенолов и их производных, которые при авто- и ЭИ-окислении образуют сильно окрашенные розово-желтые или зеленые продукты. Хотя коэффициенты их УФ-поглощения заметно выше (табл. 3) коэффициентов УФпоглощения хинониминовых производных (табл. 1), наличие продуктов окисления коренным образом изменяет УФ-спектр фенола и прямое спектрофотометрическое определение оказывается невозможным. Выделение исходного фенола при помощи тонкослойной хроматографии применительно к менее реакционноспособным одноатомным фенолам дает положительные результаты. Более активные алкилрезорцины при разделении в тонком слое дополнительно окисляются (до $70 \%$ ), и их определение возможно только при использовании внутреннего стандарта (того же фенола заданной концентрации). Для пирокатехина такой метод хроматографического разделения непригоден, вследствие полного окисления его на пластине. На основе способности пирокатехина к образованию хинонимина без дополнительного окисления нами разработан простой метод его определения. Продукты ЭИ-окисления пирокатехина интенсивную желтую (до оранжевой) окраску образуют сразу после смешивания с ААП в щелочном растворе, а образование красного хинонимина начинается только через 20 сек после смешивания. Поэтому благодаря организации измерения интенсивности желтой окраски в первые секунды и внесениям в расчет соответствующей поправки удается получить достоверные результаты.

\section{Выводы}

1. Наличие алкильных и метокси-заместителей в молекуле фенола снижает интенсивность окраски хинонимина.

2. Метильная группа в пара-положении относительно гидроксила не мешает протеканию реакции 4-метил- и 2,4,6-триметилфенолов с ААП в связи с отдалением метильного заместителя.

3. Определение многоатомных фенолов путем сочетания с ААП в составе смесей с продуктами окисления является сложным процессом, однако по сравнению с прямым спектрофотометрическим определением дает лучшие результаты.

\section{ЛИТЕРА Т У Р А}

1. Weiss, F. T., Determination of Organic Compounds: Methods and Procedures. Wiley-Interscience, New-York, London, Sydney, Toronto, 1970.

2. Eme r s o n, E. J., J. Org. Chem., 8, № 3, 417, 433 (1943).

3. P e er, H. G., Rec. trav. chim. Pays-Bas, 78, 631 (1959).

4. S vo bodova, D., Ga s parič, J., Coll. Czechosl. Chem. Comm., 33, 42 (1968).

5. L a Rue, T. A., B lakley, E. R., Anal. Chim. Acta, 31, 400 (1964).

6. Eltinger, M. E., Ruchhoft, C. C., Lishka, R. J., Anal. Chem., 23, 1783 (1951).

7. К а плин В. Т., Ф е сен ко Н. Г., Гигиена и санитария, 25, 41 (1960).

8. Е ршов Б. П., Бор и сов Ф. Б., Пластмассы, № 6, 66 (1960).

9. К а плин В. Т., Л у рье Ю. Ю. и др., Гидрохим, мат., 41, 84 (1966).

10. Svobodova, D., Gasparič,, J., Acta Fac. Pharm. Univ. Comeniana, 22, 7 (1972).

11. Foretaine, J. E., Joshipena, Р. В., и др. Anal. Chem., 46, 62 (1974).

12. К и р со У., Уйб о п у у Х. и др., Реакционная способность орг. соед., 10, 625 (1973). 
13. Кирсо у., Туулметс А. и др., Реакционная способность орг. соед., 13, № 3 (1976).

14. Л и лл е Ю. Э., Б и т те р Л. А., Авт. свид. СССР, № 292944. Открытия, изобретения, промышленные образцы, товарные знаки, 48, 93 (1971).

15. T a f t, R. W., Evans, H. D., J. Chem. Phys., 27, 1427 (1957).

16. К и рсо У. Э., Г у бе рг риц М. Я., Ж. прнкл. хим., 45,835 (1972).

17. Бр одская Б., Ки с с У., Гу бе ргриц М., Изв. АН ЭССР. Хим. Геол., 23, 290 (1974) и 24,37 (1975).

18. Кирсо У. Э., Берновская Н. А., Губергриц М. Я., Химия тверд. топл., № 2,100 (1973).

\section{Ннститут химии \\ Академии наук Эстонской ССР}

Поступила в редакцию 28/II 1975

\section{Uuve KIRSO}

\section{FENOOLIDE MÄRAMINE 4-AMINOANTIPURIINIGA}

Uuriti erineva struktuuriga fenoolide värvusreaktsiooni, mida põhjustab 4-aminoantipüriin. Katsetatud 45 fenoolist andsid 29 värvilise kinoonimiini, kusjuures kõigi asendatud fenoolide värvus oli nõrgem kui oksübenseenil. Märgiti ortoasendajate hüperkroomset ja kahe metaasendaja batokroomset toimet neeldunud värvusele. Paraasendis oleva metüülgrupi eraldumise tõttu reageerisid värvainega ka 4-metüül- ja 2,4,6-trimetüülfenool.

Fenoolide oksüdeerimisel tekkivates segudes oli laguproduktide segava toime tôttu eriti raske määrata mitmeaatomilisi fenoole. Siiski andis 4 -aminoantipüriini värvusreaktsiooni kasutamine paremaid tulemusi kui otsene spektrofotomeetriline määramine.

\section{Uuve KIRSO}

\section{DETERMINATION OF PHENOLS WITH 4-AMINO-ANTIPYRIN}

At a study of the 4-amino-antipyrin (AAP) reaction with 45 various substituted phenols, the formation of red-coloured product (chinon-imine) was stated only for 29 compounds.

The colour intensity is closely dependent upon the nature of the substituent, the highest intensity being found for the simplest phenol (oxybenzene). At the reaction of para-substituted phenols with AAP, the p-methyl group was found to be expelled from the phenols molecule in the case of 4-methyl- and 2,4,6-trimethylphenols.

The possibility of a satisfactory determination of phenols with AAP in the mixture of its oxidation products is strongly limited, which does not limit the wide use of the method as a more sensible one in comparison with the direct determination by UV-absorption spectroscopy. 